\title{
Larval activity levels and delayed metamorphosis affect post-larval performance in the colonial ascidian Diplosoma listerianum
}

\author{
Dustin J. Marshall ${ }^{1, *}$, Jan A. Pechenik ${ }^{1,2}$, Michael J. Keough ${ }^{1}$ \\ ${ }^{1}$ Department of Zoology, University of Melbourne, Victoria 3010, Australia \\ ${ }^{2}$ Department of Biology, Tufts University, Medford, Massachusetts 02155, USA
}

\begin{abstract}
It is becoming widely recognized that extending the larval period of marine invertebrates, especially of species with non-feeding larvae, can affect post-larval performance. As these carry-over effects are presumed to be caused by the depletion of larval energy reserves, we predicted that the level of larval activity would also affect post-larval performance. This prediction was tested with the cosmopolitan colonial ascidian Diplosoma listerianum in field experiments in southern Australia. Diplosoma larvae, brooded in the parent colony, are competent to settle immediately after spawning, and they remain competent to metamorphose for $>15 \mathrm{~h}$. Some larvae were induced to metamorphose 0 to $6 \mathrm{~h}$ after release, whilst others were induced to swim actively by alternating light and dark periods for up to $3 \mathrm{~h}$ prior to metamorphosis. Juvenile colonies were then transplanted to a subtidal field site in Port Phillip Bay and left to grow for up to $3 \mathrm{wk}$. Extending the larval period and increasing the amount of swimming both produced carry-over effects on post-larval performance. Colonies survived at different rates among experiments, but larval experience did not affect survival rates. Delays in metamorphosis and increased swimming activity did, however, reduce colony growth rates dramatically, resulting in $50 \%$ fewer zooids per colony. Moreover, such colonies produced initial zooids with smaller feeding structures, with the width of branchial baskets reduced by 10 to $15 \%$. These differences in branchial basket size persisted and were still apparent in newly budded zooids 3 wk after metamorphosis. Our results suggest that, for $D$. listerianum, larval maintenance, swimming, and metamorphosis all use energy from a common pool, and increases in the allocation to maintenance or swimming come at the expense of post-larval performance.
\end{abstract}

KEY WORDS: Delayed metamorphosis $\cdot$ Ascidian $\cdot$ Carry-over effects $\cdot$ Larvae $\cdot$ Settlement

\section{INTRODUCTION}

The ability of marine invertebrate larvae to delay metamorphosis after becoming physiologically competent to metamorphose has been well documented for larvae in a variety of phyla (reviewed by Pechenik 1990). This ability of competent larvae to remain swimming in the absence of certain specific environmental cues is generally believed to promote metamorphosis of individuals into habitats most likely to support survival to adulthood (Thorson 1950, Scheltema 1971, Crisp 1974, Pechenik 1990). However, it is becoming increasingly apparent that delaying metamorphosis

*Email: d.marshall@zoology.unimelb.edu.au can also incur serious costs. Increased exposure of larvae to planktonic predation is an obvious potential cost (Pechenik 1999). More surprisingly, however, delaying metamorphosis has been found to decrease juvenile growth rates significantly and often dramatically in a variety of species, particularly those that produce lecithotrophic larvae (reviewed by Pechenik et al. 1998, Pechenik 1999). Such 'carry-over' effects, in which larval experiences decrease the fitness or potential fitness of post-metamorphic individuals, have been documented in a number of species from a range of phyla (Pechenik et al. 1998, Wendt 1998, Maldonado \& Young 1999, Roberts \& Lapworth 2001). 
The main larval experience examined to date has been the simple prolongment of the planktonic period, which, in non-feeding larval stages, most likely results in energy reserves being depleted. Exposure to toxicants may also affect post-metamorphic performance (Pechenik et al. 1998), and, at least for species with lecithotrophic larvae, larval size may also influence post-metamorphic events (Moran \& Emlet 2001). In this latter case, it is presumed that larger larvae have more energy reserves available at the time of attachment and metamorphosis. If the planktonic phase competes with metamorphosis for energy reserves, then we predict that variation in larval activity patterns will also affect the energy remaining for metamorphosis by changing rates of energy consumption. The most obvious energy demand on larvae is swimming. Ascidians, with their non-feeding, swimming, tadpole larvae, are strong (although previously untested) candidates for carry over effects. In this study we tested whether delayed metamorphosis and increased swimming activity have carry over effects on growth and survival for the colonial ascidian Diplosoma listerianum. There have been few attempts to identify potential sources of carry-over effects in marine invertebrates. However, Wendt (1996) found that the ancestrulae of Bugula neritina had smaller feeding structures when metamorphosis was delayed. Therefore, we also determined the effect of delayed metamorphosis and increases in swimming activity on the size of feeding structures in newly metamorphosed juveniles of $D$. listerianum.

Diplosoma listerianum proved to be an excellent organism for this study. It is widely distributed in temperate ports and harbours and has an encrusting growth form, with zooids embedded in a fragile tunic. The zooids bud and reproduce independently of each other (Bishop \& Sommerfeldt 1999) and this growth form allows colonies to grow very rapidly. The lecithotrophic larvae are readily obtained by exposing adult colonies to light, and most are competent to metamorphose within minutes of their release from the parent. Importantly, like many ascidian larvae (Svane \& Young 1989), the larvae of $D$. listerianum tend to be inactive in constant light and swim actively in response to shadow, providing a means of varying the rate at which larvae expend energy.

\section{MATERIALS AND METHODS}

General methods. Obtaining and handling larvae: The experiments were done in the field in the Australian spring from September to the end of December 2001. We obtained Diplosoma listerianum larvae from reproductively mature colonies that grew on Perspex sheets at Breakwater pier, Williamstown (Melbourne).
When larvae were required, the Perspex sheets were brought into the laboratory and maintained in constant darkness in recirculating aquaria for 24 to $48 \mathrm{~h}$. We then exposed the colonies to bright light and subsequently collected the larvae that were spawned. Colonies generally began releasing larvae 1 to $2 \mathrm{~h}$ after exposure to light. The spent colonies were then returned to the field and allowed to remain there for at least $1 \mathrm{wk}$ before again being used as brood-stock.

In order to investigate the effects of delayed metamorphosis, we must first know when larvae become competent to metamorphose and be able to prevent and/or induce metamorphosis at well-defined times. Excess $\mathrm{K}^{+}$in seawater has proven to be an effective cue for larvae in a number of phyla (Pechenik \& Heyman 1987, Wendt \& Woollacott 1995). Although ascidian larvae were thought to be insensitive to such cues, larvae of Halocynthia roretzi can be induced by $\mathrm{K}^{+}$at 20 or $50 \mathrm{mM}$ (Matsumura et al. 1999). Similarly, the larvae of Herdmania momus (Degnan et al. 1997) and Ascidia nigra (J.A.P. unpubl. data, Bermuda Biological Laboratory, 1986) respond to excess $\mathrm{K}^{+}$in the range of 20 to $40 \mathrm{mM}$. Consequently, we tested whether the larvae of Diplosoma listerianum could be induced to metamorphose in the presence of excess $\mathrm{K}^{+}$. In the first experiment (Expt A), 3 concentrations were tested on larvae: 10,20 , and $30 \mathrm{mM}$ excess $\mathrm{K}^{+}$, along with a control treatment. After the results of this experiment, we added a fourth concentration, $5 \mathrm{mM}$, in the second experiment (Expt B). All seawater was filtered to $0.45 \mu \mathrm{m}$ before use, and $\mathrm{K}^{+}$concentrations were raised by adding appropriate amounts of reagent-grade $\mathrm{KCl}$. Larvae to be tested were first transferred (with a very small amount of seawater) into a bath $(500 \mathrm{ml})$ of test solution and then into the wells of 24-well, plastic, tissue-culture plates. The test solution was replaced regularly so as not to alter the concentration of the test solution. Four wells were used per treatment, with either 2 larvae (Expt A) or 4 larvae (Expt B) per well. The number of individuals attached and metamorphosed was recorded after $1 \mathrm{~h}$ and again after $2 \mathrm{~h}$. Four wells of filtered seawater, with larvae, served as controls. All experiments were conducted at room temperature $\left(22\right.$ to $\left.23^{\circ} \mathrm{C}\right)$.

We were interested in determining when Diplosoma listerianum larvae become competent to metamorphose and how long they can have their metamorphosis delayed whilst being capable of successful metamorphosis. Therefore we tested their ability to metamorphose immediately after release and again at 11,12, and $15 \mathrm{~h}$ after release to see how long larvae could delay their metamorphosis without losing the ability to metamorphose (hereafter referred to as Expt C). We delayed the metamorphosis of larvae using the method described below. For each assay, 15 to 20 larvae were exposed to $10 \mathrm{mM}$ excess $\mathrm{K}^{+}$on black-plastic plates with rough- 
ened surfaces, and another 15 to 20 larvae were placed on the black-plastic plates in control seawater. Attachment and metamorphosis were assessed after $1.5 \mathrm{~h}$.

To delay the metamorphosis of Diplosoma listerianum, newly released larvae were maintained individually in the wells of 24-well, transparent-plastic, tissue-culture plates. These plates were kept under bright lights and sat upon sheets of white paper. In our experiments involving a simple delay of metamorphosis, 0 to $25 \%$ of larvae settled in the tissue-culture plates before we could transfer them to the settlement plates. After the predetermined period in delay (up to $6 \mathrm{~h})$, larvae were transferred into a bath of $10 \mathrm{mM}$ excess $\mathrm{K}^{+}$in seawater (see 'Results' for effect of $\mathrm{K}^{+}$on metamorphosis). We immediately removed the larvae from the $\mathrm{K}^{+}$bath and placed individual larvae with a small drop of the excess $\mathrm{K}^{+}$seawater solution in the corners of roughened, black Perspex plates $(11 \times$ $11 \mathrm{~cm}$, hereafter referred to as settlement plates). Each settlement plate had a single, differentially delayed larva in each corner. The droplets were prevented from drying out by placing water-soaked paper towel next to each plate and then covering the plate with opaque plastic covers. After about $1 \mathrm{~h}$, larvae that had not attached were discarded; those that had attached had their excess $\mathrm{K}^{+}$droplet replaced with seawater. The position of the attached metamorphs was marked with a small dot of nail polish or circled with a pencil.

The settlement plates with attached larvae were held overnight in a flow-through aquarium before being transferred to the field. In the field, we attached the plates to a large $(90 \times 90 \mathrm{~cm}$; 8 small plates per backing plate) backing plate using stainless-steel bolts. The settlement plates were arranged on the backing plate so that their position on the backing plate was haphazard. The backing plates were then hung horizontally with the experimental plates facing down at a depth of $\sim 2 \mathrm{~m}$ below mean low tide. We conducted a census on the plates weekly, and at each census, we checked colony survival and counted the number of zooids in each colony. We carried out each census of growth in the field with the settlement plates held in a shallow pool filled with seawater in order to minimise the exposure of colonies to air. Diplosoma listerianum colonies tend to fragment after about $3 \mathrm{wk}$ in the field (D.J.M. pers. obs.). Therefore we discontinued the experiments after $3 \mathrm{wk}$, as colony measurements could become unreliable due to fragmentation. Finally, for Expt 1, we were unable to collect data in the first week of the experiment.

Increased larval swimming activity: We were interested in the effect that increased larval activity might have on the performance of adult Diplosoma listerianum. Ascidian tadpoles show a 'shadow response' whereby they swim vigorously when a shadow passes over them (Svane \& Young 1989). We hypothesised that by exposing some larvae to an alternating light:dark cycle we could induce them to swim much more than larvae kept in constant light. Collection of the larvae was as described above, and larvae were placed in 24-well, tissue-culture plates. We placed the tissue-culture plates on sheets of white paper in a light-tight box with a fluorescent light fitted in the lid. The light was fitted to a timer that could be adjusted to turn on and off at different intervals. We used 2 different light:dark treatments in our experiments. For one experiment, we exposed some larvae to an alternating light:dark cycle of 35:35 s for $1 \mathrm{~h}$. This light:dark cycle resulted in a number ( $\sim 50 \%)$ of larvae attaching to the culture plates. Therefore we used a different light:dark cycle for the remaining experiments. For the second and third experiments involving larval swimming, we used a cycle of $75 \mathrm{~s}$ light:5-6 s dark. This light:dark cycle reduced the number of larvae that attached to the culture plates to $\sim 30 \%$.

To assess the effects of the light:dark cycle, we determined the proportion of larvae swimming and the duration of swimming bursts for freshly spawned larvae in constant light $(n=10)$ and larvae $(n=10)$ in the light:dark cycle over a $3 \mathrm{~h}$ period. At regular intervals, we determined the number of larvae swimming under constant light and the number of larvae swimming in response to the shadow mimic. For larvae experiencing shadow mimics, larval activity was assessed as soon as the light went off. In addition, 3 larvae in each group, chosen at random each time, were observed to see how long they kept swimming once they began. Finally, at the end of the $3 \mathrm{~h}$ period, larvae that had been maintained in constant light were transferred to the shadow mimic treatment. Their responses were noted a few minutes later, to quantify the degree to which these individuals were still capable of swimming at the end of the $3 \mathrm{~h}$ in constant light.

Experimental designs. We examined the effects of delaying metamorphosis for varying periods and the effects of variation in larval activity on post-metamorphic growth in 5 separate experiments (Table 1). The periods of delay for the first experiment were selected as we felt that they represented a lower-end value of their maximum delay time (see 'Results'). Once we established that delays of 6 and $3 \mathrm{~h}$ had an effect, we attempted to determine the effects of shorter delays, with and without increasing the levels of larval activity. For Expt 1, we also measured the diameter of the branchial baskets of the colonies after $3 \mathrm{wk}$ in the field. Pilot studies indicated that the diameter of branchial baskets was a good predictor of overall branchial basket size and was the most convenient dimension to measure accurately (D.J.M. pers. obs). We transported the colonies back to the laboratory, where we measured the branchial baskets of 8 haphazardly chosen zooids from each colony and used 
Table 1. Diplosoma listerianum. Summary of experiments examining the effects of delayed metamorphosis and swimming on post-metamorphic growth. 'Swimming A' refers to a light:dark cycle of 35:35 $\mathrm{s}$; 'swimming B' refers to a light:dark cycle of 75:5 s. See 'Materials and methods' for a more detailed description

\begin{tabular}{|c|c|c|c|}
\hline Expt & Date & Treatment & $\mathrm{N}$ \\
\hline 1 & 13 Oct 2001 & $\begin{array}{l}\text { No delay } \\
3 \text { h delay } \\
6 \text { h delay } \\
\text { No delay/no } \mathrm{KCl}^{\mathrm{a}}\end{array}$ & $\begin{array}{l}11 \\
14 \\
14 \\
11\end{array}$ \\
\hline 2 & 24 Oct 2001 & $\begin{array}{l}\text { No delay } \\
1 \mathrm{~h} \text { delay } \\
1 \mathrm{~h} \text { swimming } \mathrm{A}\end{array}$ & $\begin{array}{r}7 \\
18 \\
8\end{array}$ \\
\hline 3 & 30 Oct 2001 & $\begin{array}{l}\text { No delay } \\
2 \mathrm{~h} \text { delay } \\
3 \mathrm{~h} \text { delay } \\
6 \mathrm{~h} \text { delay }\end{array}$ & $\begin{array}{l}20 \\
32 \\
15 \\
16\end{array}$ \\
\hline 4 & 13 Nov 2001 & $\begin{array}{l}\text { No delay } \\
3 \text { h swimming } B \\
3 \text { h delay }\end{array}$ & $\begin{array}{r}14 \\
17 \\
9\end{array}$ \\
\hline 5 & 20 Nov 2001 & $\begin{array}{l}\text { No delay } \\
3 \text { h swimming } B \\
3 \text { h delay } \\
6 \text { h delay }\end{array}$ & $\begin{array}{l}25 \\
25 \\
21 \\
26\end{array}$ \\
\hline \multicolumn{4}{|c|}{$\begin{array}{l}\text { aAs a control for the effects of excess } \mathrm{K}^{+} \text {, we included a } \\
\text { second control where no } \mathrm{KCl} \text { was used to induce meta- } \\
\text { morphosis }\end{array}$} \\
\hline
\end{tabular}

the mean of these measures for each colony in each treatment ( $\mathrm{n}=8,9,9$ and 12 for no delay/no $\mathrm{KCl}$, no delay, $3 \mathrm{~h}$ delay and $6 \mathrm{~h}$ delay, respectively). For Expts 4 and 5, we measured the diameter of the branchial basket of the largest zooid (of the pair) $12 \mathrm{~h}$ after attachment for each juvenile colony in each treatment prior to transporting the larvae to the field.

Data analysis. All data were checked to ensure that they met the assumptions for the appropriate statistical analyses. Colony growth data were analysed using analysis of variance (ANOVA), with larval treatments as a fixed factor. The dependent variable was the number of zooids at a particular time, and that variable was square-root transformed to remove the skewed distribution that resulted from colony growth occurring in 2-dimensions. For experiments with replicates spread across multiple backing plates, we checked for variation in treatment effects among backing plates by including backing plates as an additional, random factor in analyses. When such effects were absent, we dropped the backing-plate term from the final model. Following the initial ANOVA, we tested effects of delay and swimming using planned comparisons. In general, we first compared the colony size of animals that were simply delayed with controls. If that comparison was non-significant, we compared these 2 groups to the larvae that were delayed with swimming. If delayed larvae grew more slowly than controls, we compared the delayed, swimming larvae to those that were delayed only.

Mortality data were analysed using contingency tables, with mortality at the end of the experiment as the dependent variable. The analysis sequence was the same as described above, with initial analysis of a treatment $\times$ mortality table, followed by comparisons of subsets of treatments.

Because we expected prolonged larval periods to reduce post-larval performance, all comparisons of delayed larvae to controls or $\mathrm{K}^{+}$-treated controls were 1-tailed.

\section{RESULTS}

\section{Larval competence}

$\mathrm{K}^{+}$induced Diplosoma listerianum larvae to metamorphose. For Expt A, there were differences in rates of initiation of metamorphosis after $1 \mathrm{~h}$ (1-way ANOVA, $F_{3,16}=4.058, \mathrm{p}=0.025$, Fig. 1 ), with few larvae metamorphosing in controls, and $60 \%$ metamorphosis in the $10 \mathrm{mM}$ excess $\mathrm{K}^{+}$treatment. These rates differed significantly (Dunnett's test, $\mathrm{p}=0.009$ ). The effects of the other $\mathrm{K}^{+}$treatments were intermediate between controls and $10 \mathrm{mM}$, but did not differ significantly from control values (Dunnett's test for 20 and $30 \mathrm{mM}, \mathrm{p}=0.333$ and 0.833 , respectively). No larvae initiated metamorphosis after the first hour (Fig. 1). Results for Expt B were similar, with significant differences among treatments $\left(F_{4,15}=3.233, \mathrm{p}=0.042\right)$, and only the $10 \mathrm{mM} \mathrm{K}^{+}$treatment significantly increasing metamorphosis (Dunnett's test, $\mathrm{p}=0.039$ ). The 20 and
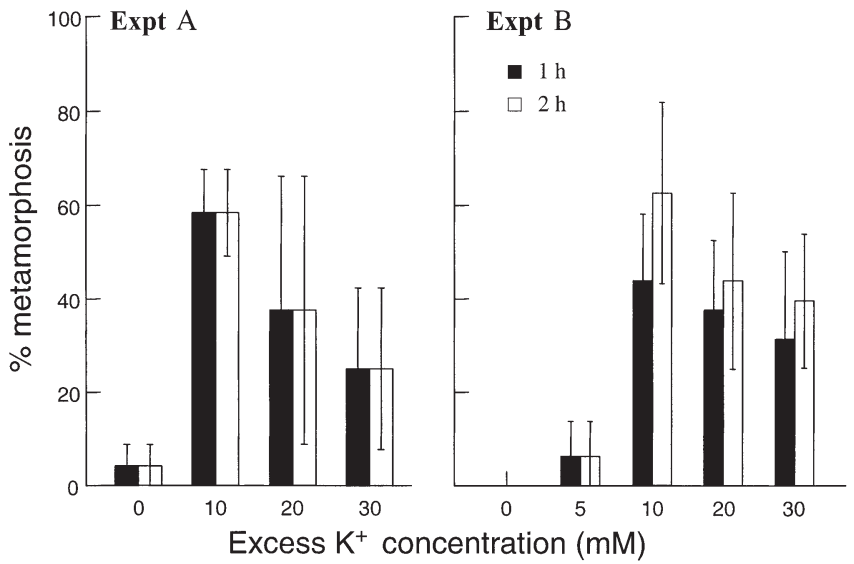

Fig. 1. Diplosoma listerianum. Initiation of metamorphosis in larvae after exposure to additional $\mathrm{KCl}$. Mean percentage of larvae initiating metamorphosis $( \pm \mathrm{SE})$ at different times after larval release is shown for Expts A and B 
$30 \mathrm{mM}$ treatments again had little effect (Dunnett's test, $\mathrm{p}=0.084$ and 0.173 , respectively), and the additional treatment, $5 \mathrm{mM}$ excess $\mathrm{K}^{+}$, produced results almost identical to the controls (Fig. 1, Dunnett's test, $p=0.982$ ). Larvae continued to initiate metamorphosis after the first hour, but the pattern among treatments did not change (Fig. 1).

In Expt C, Diplosoma listerianum larvae were capable of extended larval periods. After 13 or $14 \mathrm{~h}, 95 \%$ of 40 larvae attached and initiated metamorphosis within $1 \mathrm{~h}$ of exposure to $\mathrm{K}^{+}$or the presence of a shaded surface. Even after 15 h, 7 out of 10 larvae metamorphosed successfully.

\section{Effects of prolonged larval periods}

Delaying the onset of metamorphosis had severe consequences for adults, with the strongest effects on growth. Delays of 3 or $6 \mathrm{~h}$ had consistent effects, whereas shorter delays were more variable in their impacts. Effects on mortality, however, were weak, and overall mortality varied among experiments (Fig. 2).

The highest mortality occurred in Expt 5 and few colonies survived beyond the first week in the field. Mortality was also high in Expt 3, with $>50 \%$ in most treatments. In contrast, the first experiment had $<10 \%$ mortality overall. Mortality was little affected by experimental treatments. The overall $\chi^{2}$ was not significant in any experiment, and only 1 of 7 of the planned comparisons showed any effect (Table 2), with a $3 \mathrm{~h}$ delay causing slightly higher mortality in the first experiment (Fig. 2).

Growth of Diplosoma listerianum colonies was affected by delays in attachment, and these effects were independent of the backing plates. The experimental convenience of placing experimental substrata onto several larger backing plates in Expts 1 and 4 had little effect on colony size at particular time periods, with neither an effect of backing plate overall (Expt 1, Weeks 2 and 3: $F_{1,59}=3.48, \mathrm{p}=0.067$, and $F_{1,56}=0.58$, $\mathrm{p}=0.450 ;$ Expt 4, Weeks 1, 2 and 3: $F_{1,27}=0.31, \mathrm{p}=$ $0.584, F_{2,27}=2.41, \mathrm{p}=0.133, F_{2,27}=2.18, \mathrm{p}=0.053 ;$ Expt 5, Week 1: $\left.F_{1,89}=2.217, \mathrm{p}=0.140\right)$, nor, more importantly, a treatment $\times$ backing-plate interaction (Expt 1, Weeks 2 and 3: $F_{3,59}=0.61, \mathrm{p}=0.609$ and $F_{3,56}=0.59$, $\mathrm{p}=0.622$; Expt 4, Weeks 1, 2 and 3: $F_{2,27}=2.18, \mathrm{p}=$ $0.133, F_{2,27}=1.35, \mathrm{p}=0.279, F_{2,27}=4.25, \mathrm{p}=0.733$; Expt 5, Week 1: $\left.F_{3,89}=0.82, \mathrm{p}=0.489\right)$. Accordingly, these terms were omitted from the statistical models.

Growth rates of control colonies varied among experiments, but generally increased through the experimental series. In the first experiment, colonies from larvae whose metamorphosis was delayed by 3 or $6 \mathrm{~h}$ were much smaller than control colonies or those
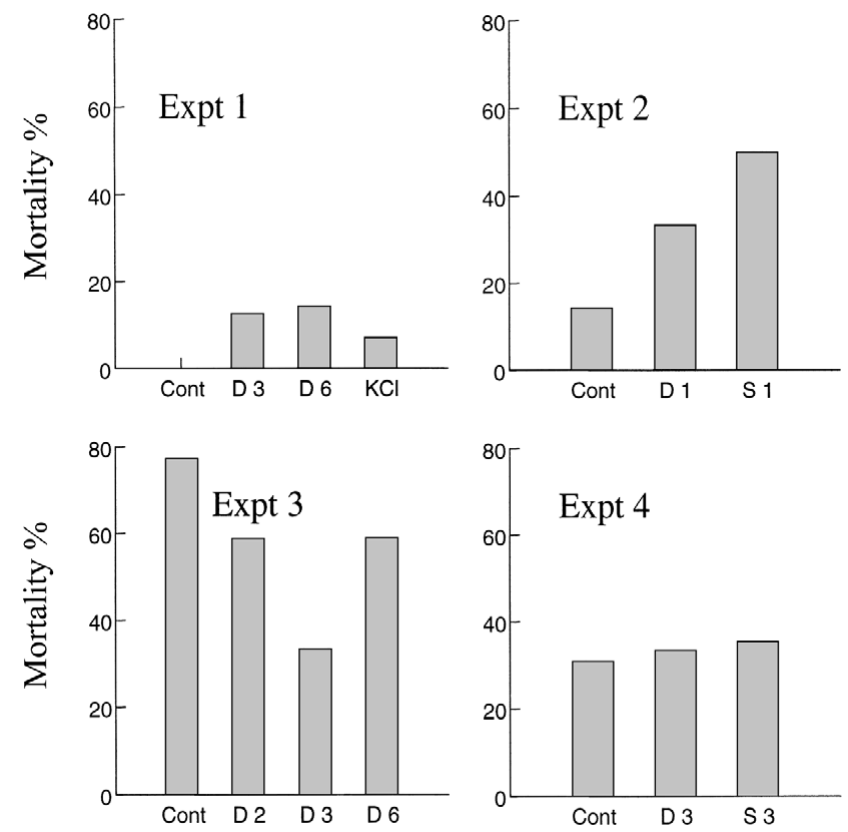

Fig. 2. Diplosoma listerianum. Mortality of colonies at the end of Expts 1, 2, 3 and 4 (see Table 1). Mean percentage mortality in different treatments is shown for Expts 1 to 4

exposed to $\mathrm{K}^{+}$, with approximately $2 / 3$ of the number of zooids (Table 3, Fig. 3). Delays of 3 and $6 \mathrm{~h}$ had similar effects. A much shorter delay of attachment in the second experiment still produced a similar reduction in size after 3 wk (planned comparison, control vs $1 \mathrm{~h}$ delay, $\mathrm{df}=1,18, \mathrm{p}=0.033$ ). The third experiment used

Table 2. Analysis of mortality at end of experiments. For each experiment, an overall test was made of differences in mortality among treatments. The other comparisons follow the same protocol outlined for the analyses of growth

\begin{tabular}{|c|c|c|c|}
\hline Expt and test & $\chi^{2}$ & df & $\mathrm{p}$ \\
\hline \multicolumn{4}{|l|}{ Expt 1} \\
\hline Overall & 3.723 & 3 & 0.293 \\
\hline Control vs $\mathrm{KCl}$ & 1.615 & 1 & 0.204 \\
\hline Control-KCl vs 3 h delay ${ }^{a}$ & 2.928 & 1 & 0.044 \\
\hline Control-KCl vs 6 h delay ${ }^{a}$ & 1.362 & 1 & 0.122 \\
\hline \multicolumn{4}{|l|}{ Expt 2} \\
\hline Overall & 2.143 & 2 & 0.343 \\
\hline Control vs 1 h delay ${ }^{\mathrm{a}}$ & 0.907 & 1 & 0.171 \\
\hline Control +1 h delay vs $1 \mathrm{~h}$ swimming ${ }^{\mathrm{a}}$ & 4.840 & 1 & 0.123 \\
\hline \multicolumn{4}{|l|}{ Expt 3} \\
\hline Overall & 7.125 & 3 & 0.068 \\
\hline \multicolumn{4}{|l|}{ Expt 4} \\
\hline Overall & 0.068 & 2 & 0.967 \\
\hline Control vs 3 h delay ${ }^{\mathrm{a}}$ & 0.016 & 1 & 0.450 \\
\hline Control +3 h delay vs $3 \mathrm{~h}$ swimming ${ }^{\mathrm{a}}$ & 0.052 & 1 & 0.410 \\
\hline${ }^{\mathrm{a} O n e-t a i l e d ~ t e s t ~}$ & & & \\
\hline
\end{tabular}




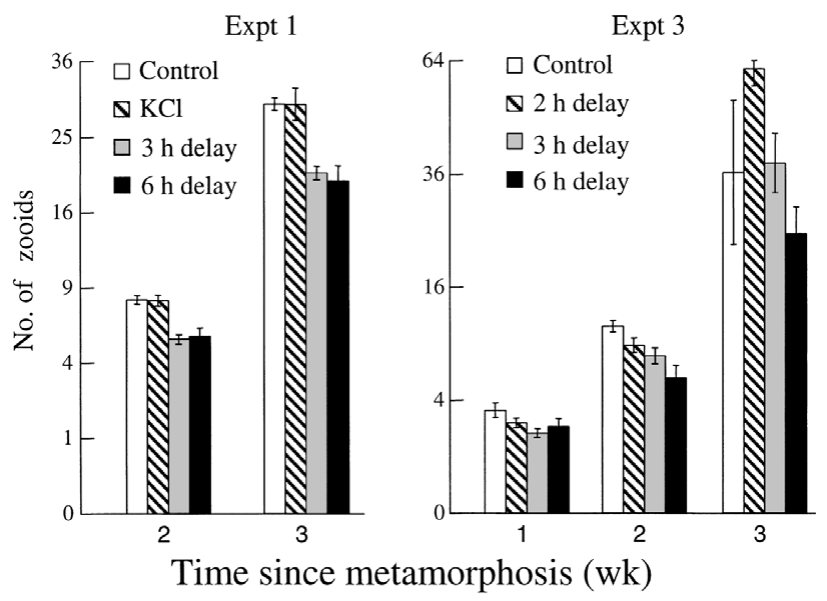

Fig. 3. Diplosoma listerianum. Growth of colonies during Expts 1 and 3. Bars show the mean number of zooids $( \pm \mathrm{SE})$ in different treatments. Data are plotted on a square-root scale, to correspond to the analyses. No data were available for Expt 1, Week 1

3 different delay periods, and growth rate of control colonies was approximately double that of the first experiment (Fig. 3). Delaying attachment by $3 \mathrm{~h}$ reduced colony growth in the first 2 wk (Table 4), although by a smaller amount than in the other experiments (Fig. 3). After $3 \mathrm{wk}$, there was no difference from the controls, possibly because growth rate in the controls had fallen. Delaying attachment by $6 \mathrm{~h}$ produced similar effects, while larvae with a $2 \mathrm{~h}$ delay did not grow significantly less than controls, although the trends were in the predicted direction (Table 4, Fig. 3).

By Expt 4, colony growth rates had more than doubled again (Fig. 4), and the $3 \mathrm{~h}$ delay produced markedly smaller colonies after 3 wk (Table 5), although differences among treatments were slower to appear than in earlier experiments (Fig. 4). In Expt 5, mortality was high enough that data were available for

Table 3. Analysis of growth in Expt 1. Results of single-factor ANOVA on zooid size after $3 \mathrm{wk}$ in the field and square-root transformed numbers of zooids, together with planned comparisons, are shown

\begin{tabular}{|lccc|}
\hline & Week 2 & Week 3 & Zooid size \\
\hline Main analysis & & & \\
Treatment (p; df = 3) & 0.000 & 0.000 & 0.000 \\
Error MS & 0.098 & 0.326 & 0.362 \\
Error df & 63 & 60 & 34 \\
Comparison p-values & & & \\
Control vs KCl & 0.964 & 0.988 & 0.434 \\
Control-KCl vs 3 h delay & 0.000 & 0.000 & 0.000 \\
Control-KCl vs 6 h delay & \\
a & 0.000 & 0.000 & 0.000 \\
\hline & & & \\
\hline
\end{tabular}

Table 4. Analysis of growth in Expt 3. Results of single-factor ANOVA on square-root-transformed numbers of zooids, together with planned comparisons, are shown. na: a test that was not done because the means differed in the opposite direction

\begin{tabular}{|c|c|c|c|}
\hline & Week 1 & Week 2 & Week 3 \\
\hline \multicolumn{4}{|l|}{ Main analysis } \\
\hline Treatment $(\mathrm{p} ; \mathrm{df}=3)$ & 0.134 & 0.011 & 0.010 \\
\hline Error MS & 0.157 & 0.267 & 3.028 \\
\hline Error df & 52 & 37 & 31 \\
\hline \multicolumn{4}{|l|}{ Dunnett's test p-values } \\
\hline Control vs $2 \mathrm{~h}$ delay & 0.078 & 0.088 & na \\
\hline Control vs 3 h delay ${ }^{\mathrm{a}}$ & 0.013 & 0.030 & na \\
\hline Control vs 6 h delay ${ }^{a}$ & 0.089 & 0.001 & 0.131 \\
\hline${ }^{\mathrm{a} O n e-t a i l e d ~ t e s t ~}$ & & & \\
\hline
\end{tabular}

the first week after metamorphosis only (Table 6). In that week, larvae whose metamorphosis was delayed by $3 \mathrm{~h}$ grew much less than controls (planned comparison, $\mathrm{p}=0.005)$, while those subjected to delays of 3 and $6 \mathrm{~h}$ again produced similar growth rates (planned comparison, $3 \mathrm{~h}$ delay [swimming and non-swimming] vs $6 \mathrm{~h}$ delay, $\mathrm{p}=0.140$ ). Delayed attachment only slowed colony growth from 5 to 4 zooids (Fig. 5).

Summarizing the various experiments, delays of 3 or $6 \mathrm{~h}$ consistently produced smaller colonies after 2 or $3 \mathrm{wk}$, while shorter delays had more variable effects, with an effect of a $1 \mathrm{~h}$ delay in one experiment, but no effect of a $2 \mathrm{~h}$ delay in another. The effects of 3 and $6 \mathrm{~h}$ delays generally appeared quickly, generally being apparent $1 \mathrm{wk}$ after completion of metamorphosis. The differences in colony size between treatments at $3 \mathrm{wk}$ could, therefore, be a long-lasting effect of larval experiences, or a more proximate effect of colony-size vari-

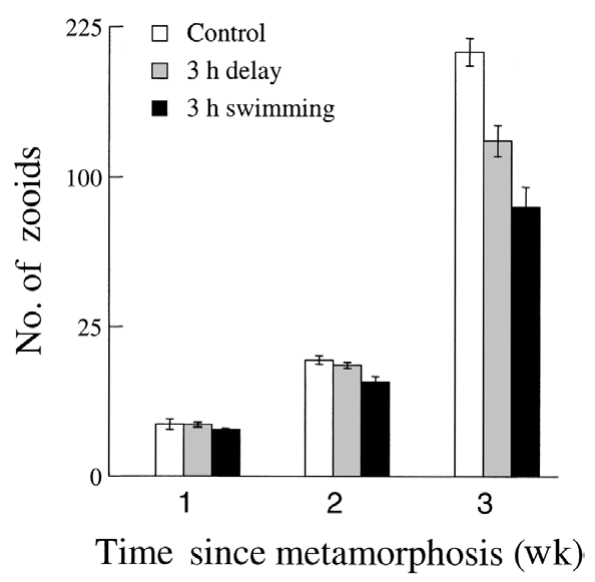

Fig. 4. Diplosoma listerianum. Growth of larvae during Expt 4. Bars show the mean number of zooids $( \pm \mathrm{SE})$ in different treatments. Data are plotted on a square-root scale, to correspond to the analyses 
Table 8. Analysis of growth during Week 2 of Expt 4, using only colonies that had 2 or 3 zooids at the end of Week 1 . The analysis was a 2-factor ANOVA, with larval treatments and number of initial zooids as the factors. The dependent variable was the square-root-transformed number of zooids, and the initial analysis was followed by planned comparisons

\begin{tabular}{|c|c|c|c|c|c|c|}
\hline Source & $\mathrm{df}$ & $F$ & $\mathrm{p}$ & $\mathrm{df}$ & $F$ & $\mathrm{p}$ \\
\hline Treatment & 2 & 3.18 & 0.067 & 2 & 6.29 & 0.012 \\
\hline Zooids at $1 \mathrm{wk}$ & 1 & 0.15 & 0.705 & 1 & 0.28 & 0.604 \\
\hline Treatment $\times$ Initial size & 2 & 2.26 & 0.134 & 2 & 0.16 & 0.857 \\
\hline Error MS & 17 & 0.24 & & 13 & & \\
\hline \multicolumn{7}{|l|}{ Planned comparisons } \\
\hline 3 h delay vs control ${ }^{\mathrm{a}}$ & & & 0.337 & & & 0.042 \\
\hline $\begin{array}{l}\text { Control + } 3 \text { h delay vs } \\
3 \text { h swimming }\end{array}$ & & & 0.011 & & & 0.057 \\
\hline${ }^{\mathrm{a}}$ One-tailed test & & & & & & \\
\hline
\end{tabular}

swimming. In contrast, those in the alternating light treatment were very active. Immediately after the light switched off, between 70 and $100 \%$ of larvae swam actively. After 2 h, 7 of 10 larvae in the variable light treatment had attached, whereas none of the constant light treatment had. Unattached larvae in the variable light treatment continued to swim actively, although the duration of swimming fell with time (mean duration (s) of swimming $\pm \mathrm{SE}, \mathrm{n}=3$ larvae, $18.3 \pm 2.5$ at $5 \mathrm{~min}$ after release, $15.0 \pm 5.2$ at $35 \mathrm{~min}, 16.3 \pm 5.5$ at $60 \mathrm{~min}, 9.7 \pm 1.5$ at $120 \mathrm{~min}, 10.0 \pm 2.0$ at $150 \mathrm{~min})$. Transferring larvae from the constantly lit to the variable lighting treatment after 150 min caused 8 out of 10 to begin swimming.

We tested the effects of swimming in 3 experiments. In the first experiment (Expt 2), larvae induced to swim did not suffer any reduction in growth after $3 \mathrm{wk}$ (1-tailed test, means in opposite direction to that pre- dicted, so no test done), but $\sim 40 \%$ of larvae attached during the exposure period. Stronger tests of the effects of larval activity were provided by Expts 4 and 5. Increased swimming had no effect on mortality (Table 2 for Expts 2 and 4), but reduced colony size markedly in Expt 4, and produced zooids with smaller branchial baskets (Table 5, Figs. 5 \& 6). There was no effect on growth after $1 \mathrm{wk}$ in Expt 5 (Table 6, Fig. 5), and no effect on size of branchial baskets, although the trend was in the same direction as for Expt 4 (Fig. 6). As for the effects of delayed attachment, effects of swimming on colony growth extended beyond initial growth rates. When we chose only colonies that reached the same size after $1 \mathrm{wk}$, we still saw effects of larval swimming (Table 8) on colony size.

\section{DISCUSSION}

We found strong carry-over effects of a prolonged larval period in Diplosoma listerianum, and increasing larval activity also reduced their post-larval performance. In both cases, carry-over effects were restricted to rates of colony growth, with little effect on colony survival.

Delaying metamorphosis by $3 \mathrm{~h}$ had strong effects on post-metamorphic growth as did delays of $6 \mathrm{~h}$, whilst the effects of shorter delays were more variable. We observed a carry-over effect from a delay of $1 \mathrm{~h}$ in one experiment, but no effect of a $2 \mathrm{~h}$ delay in another. Effects of longer delays were, however, consistent and strong. Larvae remained competent to metamorphose for at least $15 \mathrm{~h}$ after release, but the effective larval lifespan is clearly much shorter.

Causing larvae to increase their swimming activity exacerbated the effects of delaying metamorphosis,
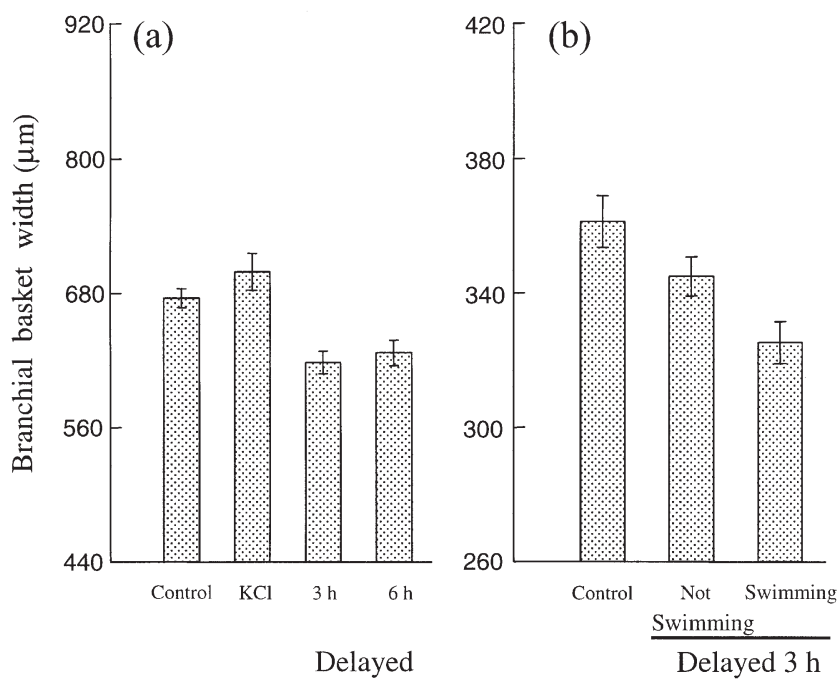

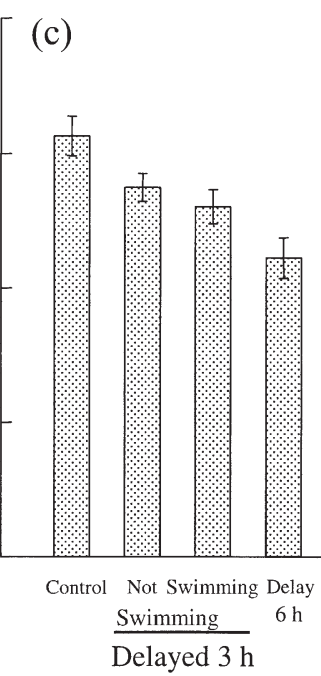

Fig. 6. Diplosoma listerianum. Size of branchial baskets of newly metamorphosed D. listerianum during 3 experiments. Mean diameter $( \pm \mathrm{SE})$ of branchial baskets in various treatments (a) after $3 \mathrm{wk}$ in the field. and $(\mathrm{b}, \mathrm{c}) 12 \mathrm{~h}$ after settlement 
although the experiments were variable in their outcomes. Of our 3 experiments, the most conclusive data came from Expt 4, in which larvae that had their metamorphosis delayed and were induced to swim performed much worse than larvae that were delayed, but allowed to remain relatively quiescent. The colonies in Expt 5 had the highest mortality, and we were only able to analyse colony growth in the first week after metamorphosis. Although the trends were consistent with an additional effect of swimming, colony sizes of swimming larvae were not significantly different from those of larvae that were just delayed. It is plausible that, given the trends, a larger effect would appear through time. The least convincing evidence came from our first swimming experiment, because around half of the larvae attached and began metamorphosis during the delay period, possibly as a result of the particular light regime. If those attached were not a random sample of larvae in each treatment, the results are difficult to interpret. In particular, if those attaching earliest were the larvae least able to withstand delays (i.e. the least well resourced), the swimming treatment may have contained a subset of well-provisioned larvae. Indeed, for this species, smaller larvae attach and metamorphose sooner than larger ones (D.J.M. unpubl. data).

The mechanism through which prolonged larval life and increased larval activity affects colony growth appears to be a reduction in the size of feeding structures. Larvae experiencing delays in metamorphosis or being induced to swim metamorphosed into zooids with narrower branchial baskets. Interestingly, branchial baskets of $3 \mathrm{wk}$ old colonies showed similar patterns. A reduction in feeding structures immediately following metamorphosis was also reported by Wendt (1996) for the bryozoan Bugula neritina. Furthermore, Wendt (1998) found strong effects of delayed metamorphosis on subsequent colony growth and reproduction. It is interesting that such effects persist through many cycles of budding within the colony, suggesting that no compensatory growth occurs - we might expect that normal-sized zooids would be produced after a few budding cycles. This reduction in feeding structures continues to affect growth rate, as we saw when we examined colony growth of subsets of each treatment group matched for colony size after 1 or $2 \mathrm{wk}$. This result is counter to the prediction by Hunter \& Hughes (1993), who considered that, in modular organisms, effects of energy shortages should be seen in the number of modules, rather than in module or larval attributes. Our results suggest that carry-over effects affect 2 of these 3 life-history aspects, and we have no data to assess the third, although, for another modular species, Bugula neritina, Marshall et al. (2002) have shown a link between larval size, colony growth/size, and larval size in the next generation.
The ultimate mechanism underlying the carry-over effects is, presumably, depletion of energy supplies in the larvae, and more specifically, energy stores that are to be used for metamorphosis. In some invertebrates with non-feeding larvae, larval energy stores may be partitioned. For example, for larvae of the bryozoan Bugula neritina, prolonged swimming does not result in major drops in protein stores (Hunter et al. 1999), although some lipids (Hunter et al. 1998) and total carbon (Wendt 2000) may decline. Similarly, in the barnacle Balanus amphitrite, lipid reserves are consumed during dispersal, while the protein stores used for metamorphosis are only consumed late in the cypris stage, if reserves become short (Shimizu et al. 1996). The energetics of dispersal and metamorphosis are not known for ascidian larvae, but the rapid onset of carry-over effects, compared to the length of the larval competency period, suggests that the energy for maintenance during swimming, active swimming, and metamorphosis comes from a common pool, rather than being strongly partitioned. The similarity in effects of delay and swimming also suggest that the same energy source is being used for maintenance and swimming.

Our experimental set-up for examining carry-over effects was artificial in 2 respects. First, recruits were growing on isolated substrata with few predators and in the absence of competition for space. Both of these processes are likely to increase colony mortality, and it would be interesting to determine whether carry-over effects persist in the face of competition. Competition among modular sessile invertebrates is size dependent (e.g. Russ 1982), and it may be that faster-growing colonies can resist competitors. In a similar way, larger colonies may be more resistant to complete mortality from predators, with colony remnants left to regenerate. It would be interesting to test whether these other influences on colony survival and size act to obscure carryover effects, or whether they enhance those effects.

That active swimming has a greater impact than quiescence on adult performance has important implications for larval dispersal and settlement. Active larval swimming has been shown to strongly affect larval dispersal and may reduce rather than increase dispersal distances (Bingham \& Young 1991, Todd et al. 1998). If active swimming has greater costs than passive drifting, then as larval energetic resources decrease larvae may decrease the proportion of time spent swimming. This hypothesis is supported by our finding that larvae exposed to a shadow mimic repeatedly over time showed a gradual reduction in the time spent swimming after each shadow. Interestingly, Davis \& Butler (1989) found that larvae of the colonial ascidian Podoclavella mollucecensis initially swam vigorously and continuously, but larvae that swam for the greatest amount of time (6 to $8 \mathrm{~min}$ ), in the field, occasionally 
ceased swimming and drifted passively. The negative effects of active swimming may result in a trade-off between the risk of dispersal and advection away from suitable settlement sites (as suggested by Bingham \& Young 1991) and the reduction in post-metamorphic performance due to active swimming.

Our results are the first demonstration that the activity patterns of lecithotrophic larvae can affect their post-larval performance. Thus larval activity patterns join delayed attachment (reviewed by Pechenik 1999), short-term nutritional stress (Pechenik at al. 1996a,b), short-term salinity stress (Pechenik et al. 2001), and initial provisioning of larvae (Moran \& Emlet 2001) as factors causing persistent, yet surprising, effects on post-metamorphic performance of marine invertebrates.

Acknowledgements. We wish to thank J. Eyster, O. Pechenik and S. de Jong for assistance in the field and laboratory. D.J.M. was supported by a Melbourne Research Scholarship; whilst in Australia, J.A.P. was supported by a Visiting Researcher Scholarship from the University of Melbourne. Earlier versions of this manuscript were greatly improved by helpful comments from A. O'Brien, D. Wendt and 1 anonymous reviewer.

\section{LITERATURE CITED}

Bingham BL, Young CM (1991) Larval behaviour of the ascidian Ecteinascidia turbinata Herdman; an in situ experimental study of the effects of swimming on dispersal. J Exp Mar Biol Ecol 145:189-204

Bishop JDD, Sommerfeldt AD (1999) Not like Botryllus: indiscriminate post-metamorphic fusion in a compound ascidian. Proc R Soc Lond B 266:241-248

Crisp DJ (1974) Factors influencing the settlement of marine invertebrate larvae. In: Grant PT, Mackie AM (eds) Chemoreception in marine organisms. Academic Press, London, p 177-265

Davis AR, Butler AJ (1989) Direct observations of larval dispersal in the colonial ascidian Podoclavella moluccensis Sluiter: evidence for closed populations. J Exp Mar Biol Ecol 127:189-203

Degnan BM, Souter D, Degnan SM, Long SC (1997) Induction of metamorphosis with potassium ions requires development of competence and an anterior signalling centre in the ascidian Herdmania momus. Dev Genes Evol 206: 370-376

Hunter E, Hughes RN (1993) The effect of diet on life-history parameters of the marine bryozoan Celleporella hyalina. J Exp Mar Biol Ecol 167:163-177

Hunter E, Okano K, Tomono Y, Fusetani N (1998) Functional partitioning of energy reserves by larvae of the marine bryozoan Bugula neritina (L.). J Exp Biol 201: 2857-2865

Hunter E, Shimizu K, Fusetani N (1999) Role of protein in larval swimming and metamorphosis of Bugula neritina (Bryozoa: Cheilostomatida). Mar Biol 133:701-707

Maldonado M, Young CM (1999) Effects of the duration of larval life on postlarval stages of the demosponge Sigmadocia caerulea. J Exp Mar Biol Ecol 232:9-21

Matsumura K, Mori S, Fusetani N (1999) Induction of larval metamorphosis in the ascidian, Halocynthia roretzi by excess potassium ion and by reduced calcium ion. J Mar Biol Assoc UK 79:1143-1144

Moran AL, Emlet RB (2001) Offspring size and performance in variable environments: field studies on a marine snail. Ecology 82:1597-1612

Pechenik JA (1990) Delayed metamorphosis by larvae of benthic marine invertebrates: Does it occur? Is there a price to pay? Ophelia 32:63-94

Pechenik JA (1999) On the advantages and disadvantages of larval stages in benthic marine invertebrate life cycles. Mar Ecol Prog Ser 177:269-297

Pechenik JA, Heyman WD (1987) Using $\mathrm{KCl}$ to determine size at competence for larvae of the marine gastropod Crepidula fornicata (L.). J Exp Mar Biol Ecol 112:27-38

Pechenik JA, Estrella MS, Hammer K (1996a) Food limitation stimulates metamorphosis of competent larvae and alters postmetamorphic growth rate in the marine prosobranch gastropod Crepidula fornicata. Mar Biol 127:267-275

Pechenik JA, Hammer K, Weise C (1996b) The effect of starvation on acquisition of competence and post-metamorphic performance in the marine prosobranch gastropod Crepidula fornicata (L). J Exp Mar Biol Ecol 199:137-152

Pechenik JA, Wendt DE, Jarrett JN (1998) Metamorphosis is not a new beginning. Bioscience 48:901-910

Pechenik JA, Gleason T, Daniels D, Champlin D (2001) Influence of larval exposure to salinity and cadmium stress on juvenile performance of two marine invertebrates (Capitella sp. I and Crepidula fornicata). J Exp Mar Biol Ecol 264:101-114

Roberts RD, Lapworth C (2001) Effect of delayed metamorphosis on larval competence, and post-larval survival and growth, in the abalone Haliotis iris Gmelin. J Exp Mar Biol Ecol 258:1-13

Russ GR (1982) Overgrowth in a marine epifaunal community: competitive hierarchies and competitive networks. Oecologia 53:12-19

Scheltema RS (1971) Larval dispersal as a means of genetic exchange between geographically separated populations of shallow-water benthic marine gastropods. Biol Bull 140: 284-322

Shimizu K, Satuito CG, Saikawa W, Fusetani N (1996) Larval storage protein of the barnacle, Balanus amphitrite: biochemical and immunological similarities to vitellin. J Exp Zool 276:87-94

Svane I, Young CM (1989) The ecology and behaviour of ascidian larvae. Oceanogr Mar Biol Annu Rev 27:45-90

Thorson G (1950) Reproductive and larval ecology of marine bottom invertebrates. Biol Rev 25:1-45

Todd CD, Lambert WJ, Thorpe JP (1998) The genetic structure of intertidal populations of two species of nudibranch mollusks with planktotrophic and lecithotrophic larval stages: are pelagic larvae 'for' dispersal? J Exp Mar Biol Ecol 228:1-28

Wendt DE (1996) Effect of larval swimming duration on success of metamorphosis and size of the ancestrular lophophore in Bugula neritina (Bryozoa). Biol Bull 191: 224-233

Wendt DE (1998) Effect of larval swimming duration on growth and reproduction of Bugula neritina (Bryozoa) under field conditions. Biol Bull 195:126-135

Wendt DE (2000) Energetics of larval swimming and metamorphosis in four species of Bugula (Bryozoa). Biol Bull 198:346-356

Wendt DE, Woollacott RM (1995) Induction of larval settlement by $\mathrm{KCl}$ in three species of Bugula (Bryozoa). Invert Biol 114:345-351

Submitted: April 17, 2002; Accepted: August 2, 2002

Proofs received from author(s): December 9, 2002 